\title{
Disaggregating Behavioral and Psychological Components of Religious and Spiritual Development across Adolescence: Variations by Geographic Location
}

\author{
Rebecca Olson
}

Follow this and additional works at: https://researchrepository.wvu.edu/etd

\section{Recommended Citation}

Olson, Rebecca, "Disaggregating Behavioral and Psychological Components of Religious and Spiritual Development across Adolescence: Variations by Geographic Location" (2016). Graduate Theses, Dissertations, and Problem Reports. 6351.

https://researchrepository.wvu.edu/etd/6351

This Thesis is protected by copyright and/or related rights. It has been brought to you by the The Research Repository @WVU with permission from the rights-holder(s). You are free to use this Thesis in any way that is permitted by the copyright and related rights legislation that applies to your use. For other uses you must obtain permission from the rights-holder(s) directly, unless additional rights are indicated by a Creative Commons license in the record and/ or on the work itself. This Thesis has been accepted for inclusion in WVU Graduate Theses, Dissertations, and Problem Reports collection by an authorized administrator of The Research Repository @ WVU. For more information, please contact researchrepository@mail.wvu.edu. 
Disaggregating Behavioral and Psychological Components of Religious and Spiritual Development across Adolescence: Variations by Geographic Location

\author{
Rebecca Olson, B.A.
}

Thesis submitted to the Eberly College of Arts and Sciences at West Virginia University in partial fulfillment of the requirements for the degree of

Master of Science

in

Psychology

\author{
Aaron Metzger, Ph.D. Chair \\ Julie Patrick, Ph.D. \\ Carol Markstrom, Ph.D.
}

Morgantown, West Virginia

2016

Keywords: adolescent, religion, spirituality

Copyright 2016 Rebecca Olson 


\begin{abstract}
Disaggregating Behavioral and Psychological Components of Religious and Spiritual

Development across Adolescence: Variations by Geographic Location
\end{abstract}

\title{
Rebecca Olson
}

Religious behavior and spirituality have been consistently found to be associated with a host of positive youth outcomes including increased grade point average (Ferris, Oosterhoff, \& Metzger, 2013) and community service (Paxton, Reith, \& Glanville, 2014) and decreased substance use (Milot \& Ludden, 2009). However, few studies have investigated how religious behavior and spirituality uniquely and interactively predict these outcomes, as well as how these associations vary across city and rural contexts. The current study sought to investigate how religious behavior and spirituality predict youth outcomes in both rural and city youth populations. Participants included 743 youth from a mid-sized University city community $(n=367)$ and rural community $(n=376)$ in a mid-Atlantic state $\left(M_{a g e}=15.87,90 \%\right.$ Caucasian, $44 \%$ male $)$. Participants completed measures of religious behavior, spirituality, grade point average, community service, substance use, and basic demographic information. Results indicated that religious behavior was positively associated with GPA, but only for youth who were high in spirituality. Religious behavior was also positively associated with community service. Finally, religious behavior was positively associated with substance use for youth who lived in a city and were also low in spirituality. 
Manuscript

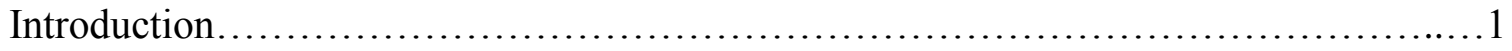

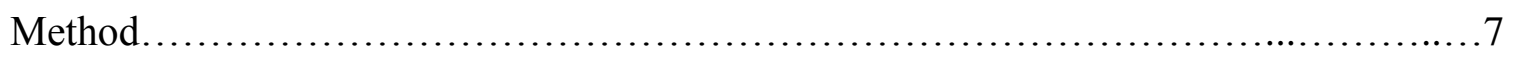

Results.......................................................................

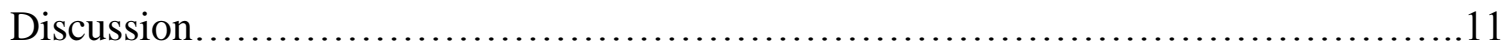

Manuscript References........................................................ 17

Appendix A: Manuscript Figures and Tables........................................... 23

Appendix B: Additional Manuscript Analyses........................................28

Appendix C: Extended Literature Review and Methods..................................29

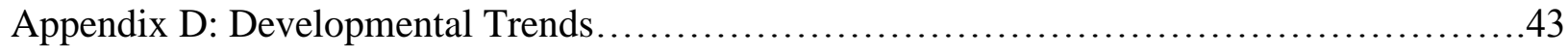

Appendix E: Four-way Interaction Analyses........................................ 45

Appendix F: Community Service Mediation.........................................49

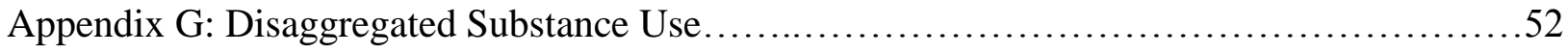

Appendix H: Additional References................................................54 
Disaggregating Behavioral and Psychological Components of Religious and Spiritual

Development across Adolescence: Variations by Geographic Location

Religious behavior and spirituality are multifaceted constructs that play a pivotal role in adolescent development. No fewer than $80 \%$ of teenagers in the United States identify as being part of a particular religion (Smith \& Denton, 2005). Further, adolescent religious behavior and spirituality have been shown to have important implications for a host of positive youth outcomes including academic performance (Milot \& Ludden, 2009), community service (Ferris, Oosterhoff, \& Metzger, 2013), and substance use (Bartkowski \& Xu, 2007). Previous research has often combined several facets of religiosity into one all-encompassing variable, so the unique and interactive role religious behavior and spirituality play in adolescent development remains unclear. Further, these constructs may operate differently in predicting adolescent outcomes within specific geographic contexts such as city compared to rural settings. The current study explored associations among religious behavior, spirituality, and three distinct developmental outcomes: academic performance (GPA), and community service, and illicit substance use and explored whether these associations varied by adolescents' geographic location.

\section{Defining and Measuring Religious Behavior and Spirituality}

Religiosity and spirituality are conceptually related in a number of ways. Specifically, people often attend religious institutions to worship a higher power whom they feel spiritually connected to. This theoretical overlap makes differentiating these constructs a difficult, yet essential task for operationalization and measurement. These similarities may also explain the divergent and inconsistent manner in which these constructs have been measured across the adolescent religious development literature. However, the distinction between religious behaviors such as church attendance, and psychological facets of religion such as importance of 
religion (e.g. Sinha, Cnaan, \& Gelles, 2007) and connectedness to a higher power (e.g. Oosterhoff, Ferris, \& Metzger, 2014) make it necessary to disaggregate these constructs and explore their unique and interactive relationship to adolescent outcomes.

One commonly agreed upon component of religiosity is participation in the organized religious practices of an institutionalized faith such as a church, synagogue, or mosque (Haug, 1998; King \& Roesner, 2008; Miller \& Thoresen, 2003). Such practices may include attending religious services and participation in religious social or community service activities (Bartkowski \& Xu, 2007; Eccles, Barber, Stone, \& Hunt, 2003; Ferris et al., 2013; Gibson, 2008; Glanville, Sikkink, \& Hernandex, 2008; Hodge, Cardenas, \& Montoya, 2001; Keretes, Youniss, \& Metz, 2004; King \& Furrow, 2004; Lam, 2002; McNamara \& Nelson, 2008; Metzger, Dawes, Mermelstein, \& Wakschlag, 2011; Milot \& Ludden, 2009; Paxton, Reith, \& Glanville, 2014; Schreck, Burek, \& Clark-Miller, 2007; Sinha et al., 2007). However, previous measures of religiosity often combine religious behaviors with other aspects of religiosity, such as the degree to which an individual feels that religion is important in their life and how connected they feel to a higher power. Adolescents may attend religious services or participate in religious social activities for a variety of reasons including social pressures such as family obligation or the opportunity to connect with their religiously involved friends. Thus, it may be particularly important to disentangle religious behavior from personal spiritual beliefs, which may signal that youth are engaging in religious behavior for intrinsically motivated reasons (Shahabi et al., 2002). These motivational differences in religiously involved youth may then contribute differently to positive youth outcomes.

Similar to research on religiosity and its many components, previous research does not point to a consistent conceptualization or empirical operationalization of spirituality. Several 
religious development theorists have argued that spirituality is a distinct construct from religious behavior in that it focuses on what is psychological and personal rather than behavioral and institutional (Haug, 1998; McNamara \& Nelson, 2008). However, research has begun to distinguish religious from non-religious spirituality (Hyland, Wheeler, Kamble, Masters, 2010). Measures of non-religious spirituality focus on overall happiness and connection to others, places, nature, and the universe (Hyland et al., 2010). In contrast, measures of religious spirituality often assess the extent to which an individual believes in and is connected to a god or other divine being which may or may not be consistent with an institutionalized faith (Benson, Scales, Sesma, \& Roehlkepartain, 2005; Good, Willoughby, \& Busseri, 2011; Hill et al., 2000). Spirituality may also refer to a deep connection one has to a sacred being outside of oneself (Benson, Roehlkepartian, \& Rude, 2003) or the influence which a higher power has on one's life (Keretes et al., 2004). Still, other definitions of religious spirituality include moral standards of living which are put forth by the divine (Haug, 1998) or the frequency one participates in spiritual practices such as meditation (Good et al., 2011). These definitions of religious spirituality share in a common theme which emphasizes a connection to or the importance of a sacred being which transcends the self. Such religious spirituality may be associated with formal religious behavior, but little research has examined whether religious spirituality and religious behavior operate similarly in predicting positive youth outcomes.

\section{Religious Behavior, Spirituality, and Positive Youth Outcomes}

Adolescent engagement in religious behavior including attendance of religious services and engagement in religious social activities has been consistently associated with a host of positive youth outcomes commonly including improved academic performance (Eccles, et al., 2003; Ferris, et al., 2013; Glanville, et al., 2008;), increased community service (Gibson, 2008; 
Lam, 2002; Paxton et al., 2014) and reduced levels of problem behaviors such as illicit substance use (Bartkowski \& Xu, 2007; Hodge et al., 2001; Milot \& Ludden, 2009; Sinha et al., 2007). Other psychological components of religion have been examined as predictors of positive youth outcomes, although findings are mixed. For instance, adolescents' trust in God has been found to be associated with reduced alcohol use, but not reductions in other illicit substances (Barkowski $\& \mathrm{Xu}, 2007)$. In addition, religious spirituality, as measured using questions exclusively about connectedness to a higher power, has been found to be negatively associated to substance use including alcohol and marijuana (Keretes et al., 2004). Although studies have examined the unique influences of religious behavior and religious spirituality during adulthood (Paxton et al., 2014), to our knowledge, no studies have directly examined and compared religious behavior and spirituality as separate and interactive predictors of commonly examined adolescent outcomes. Therefore, the current study examined the association between religious behavior and religious spirituality on three adolescent outcomes that are particularly salient in three areas of adolescents' lives. Specifically, this study examined adolescent school success (i.e. grade point average), community involvement (i.e. community service), and deviant behavior (i.e. illicit substance use), which encompass both positive and negative outcome behaviors in adolescents' lives. Therefore, inclusion of these distinct variables in the current study will provide a broad overview of how religious behavior and religious spirituality are associated with overall adolescent development.

Previous research on adolescent religious development has found significant associations between dimensions of youth religiosity and all three of these outcomes. Consistently, these studies found that church involvement was associated with increased adolescent self-reported GPA (Eccles et al., 2003; Ferris et al., 2013; Glanville et al., 2008). Religiously involved 
adolescents may be motivated to perform well in school because they attend religiously organized youth groups with peers who value academic success and avoid delinquent behavior (Glanville et al., 2008). Research has also shown that both frequency of church attendance and connectedness to a personal God have been associated with more frequent community service (Gibson, 2008; Lam, 2002; Monsma, 2007). Further, youth who internalized religious beliefs as assessed by increased religious spirituality had greater intentions of community service in the future (Keretes et al., 2004; Smetana \& Metzger, 2005). Moreover, studies which have included both religious behavior and spirituality as predictors of youth community service have found that adults who are high in both religious behavior and spirituality were found to engage in greater levels of community service than adults who are spiritual, but do not attend church services (Paxton et al., 2014). However, research has not explored whether religious behavior and spirituality interact to predict greater levels of community service during adolescence.

Finally, attendance at religious services has been found to be associated with decreased adolescent substance use including alcohol consumption and marijuana use (Bartkowski \& Xu, 2007; Sinha et al., 2007). However, findings are somewhat mixed in that some studies have found that church attendance is related to alcohol use but not marijuana (Hodge et al., 2001) while others have found the opposite pattern (Milot \& Ludden, 2009). Little research has examined the influence of spirituality on adolescent illicit substance use.

Although there have been multiple calls for research to distinguish religious behavior from the beliefs and values associated with spirituality (Benson et al., 2003; Shahabi et al., 2002), few studies have explicitly investigated potential unique links during adolescence. Additionally, recent attempts to disaggregate religious behavior from spirituality have been inconsistent in that researchers have used varying combinations of church and social event 
attendance, importance of religion, connectedness to a higher power, prayer, etc. Therefore, it difficult to articulate a clear message regarding the relative importance of religious behavior and spirituality for positive youth outcomes. As detailed above, different associations have been found depending on what components of religion and spirituality were examined and if those components were examined as one variable or separately. To understand how adolescents benefit from their religious and spiritual experiences, it is important that religious behavior be examined independent of religious spirituality in relation to a variety of outcomes including academic success, community service, and substance use.

\section{Contextual Differences in Religious Behavior and Spirituality}

In addition to examining religious behavior and spirituality separately in relation to adolescent outcomes, it is equally important to consider how these relationships may vary among youth in various geographical contexts (i.e. city vs. rural). For example, religious behavior may be particularly important for development of rural youth as it provides a unique social institution which allows youth to interact with members of the community (e.g. teachers; coaches) (Ferris et al., 2013). These relationships may be important for promoting prosocial behaviors, such as academic performance and community service opportunities, and motivate youth to avoid delinquent behaviors such as substance use. Further, urban youth have been found to be in closer proximity to religious institutions, though interactions within these religious institutions has been associated with lower substance use for rural youth (Mason, Schmidt, \& Mennis, 2012). However, little research has examined dimensions of religiosity among youth from different contexts in the same study, so the relative importance of religious behavior and spirituality in predicting positive youth outcomes for city vs. rural youth has not been directly explored. 
Given these conceptual and methodological gaps in the current literature, the first goal of the current study was to disentangle the unique effects of religious behavior and spirituality on adolescent academic performance, community service, and illicit substance use. It was hypothesized that religious behavior and spirituality would be uniquely and positively associated with academic performance and community service and negatively associated with substance use. In addition, it was hypothesized that spirituality would strengthen associations between religious behavior and youth outcomes, resulting in an even higher academic performance, increased community service, and decreased substance use for youth who are both highly engaged in religious behavior and religious spirituality.

The final aim of the current study was to examine if associations between religious behavior, spirituality, and positive youth outcomes was different for youth who live in a rural versus city context. It was hypothesized that religious behavior and spirituality would be more strongly associated with positive youth outcomes for rural youth. Analyses will control for a number of demographic variables which have been associated with religious behavior and spirituality including adolescent gender (Flor \& Knapp, 2001; Smith, Denton, Faris, \& Regnerus, 2002), adolescent age (Hackerman \& King, 1998; Keretes et al., 2004; Smith et al., 2002), and parental education (Shahabi et al., 2002).

\section{Method}

\section{Participants}

Participants consisted of 743 ninth- through twelfth grade students from in a mid-sized University city $(n=367)$ and a rural community $(n=376)$ located in a mid-Atlantic state, between, on average, six and 15 miles from the center of town. Participants (44\% male) ranged in age from 13-20 $(M=15.86, S D=1.28)$. In terms of race/ethnicity, $90 \%$ of adolescents 
reported being Caucasian, 4\% African American, 2\% Asian, 1\% Hispanic, and $<1 \%$ Native American. Approximately $90 \%$ of participants had their mother and $67 \%$ had their father living with them in the household and $86 \%$ of moms and $78 \%$ of dads had a high school education or above.

\section{Procedure}

High school students were recruited through their schools. Ninth- through twelfth-grade students were recruited in their social studies classrooms and questionnaires were administered in these classrooms to students who obtained parental consent and assented to participate in the study. Members of the research team were present to explain assent forms and answer participants' questions about the surveys as they were being administered in both schools. Students who participated in the survey were entered into a random drawing to receive cash prizes (16 at each school) ranging from $\$ 25$ to $\$ 100$.

\section{Questionnaire measures.}

Demographics. Adolescents reported their age, gender, and parent's education.

Religious behavior and Community Service. Church involvement (3 items; e.g. "How often do you attend religious services") and community service (5 items; e.g. "How often do you volunteer to clean up your neighborhood, school or community") were assessed using subscales of an organized activity involvement measure based on previous research (Metzger, 2009). Each were rated on a 5-point Likert scale ranging from 1 (never) to 5 (very often). The internal reliability of the church involvement scale is $\alpha=.91$. The internal reliability of the community service scale is $\alpha=.78$.

Religious Spirituality. Adolescent spirituality was measured using 7 items from the Spiritual Transcendence Index (e.g. "I maintain an inner awareness of God's presence in my 
life"; "My spirituality gives me a feeling of fulfillment") (Seidlitz et al., 2002). Responses were given on a 6-point Likert scale ranging from 1 (strongly disagree) to 6 (strongly agree). The internal reliability of this scale is $\alpha=.97$.

GPA. Adolescents self-reported their grades in school using a 7-point Likert scale $(7=$ mostly $A$ 's; $6=$ some $A$ 's, some $B$ 's; $5=$ mostly $B$ 's; $4=$ some $B$ 's, some $C$ 's; $3=$ mostly $C$ 's; $2=$ some C's, some D's; 1 = mostly D's or lower .

Illicit substance use. Adolescents' illicit substance use was measured using a 5-item subscale (i.e., had at least one drink of alcohol, gotten drunk off alcohol, smoked cigarettes, smoked marijuana, used prescription pills that were not meant for you) based on previous research (Ferris, et al., 2013; Metzger et al., 2009). Adolescents were asked how often they used these substances in the last 30 days on a 4-point Likert scale ranging from 1 (never) to 4 (often). The internal reliability of this scale is $\alpha=.85$.

\section{Planned Analyses}

Three linear regression models investigated unique and interactive associations between religious behavior, spirituality, geographic context, and three dependent variables: adolescent academic performance, community service, and substance use. In the first step of each regression, adolescent reports of each dependent variable, respectively, were regressed on adolescent age, gender, context (city vs. rural), and parents' education. Adolescent religious behavior, spirituality, and location were then entered into the second step. In the third and fourth step, two- and three-way interaction terms were included, respectively.

\section{Results}

\section{Preliminary analyses}


Missing Data. Data were missing for several variables. One participant did not report either age or gender and an additional participant did not report gender. Both participants were removed from the sample leaving a final sample of 741 participants. In addition, there were several missing data points on items for each of the following scales: spirituality, substance use, and community service. Mean scores were created based on the items students did complete. Two participants were missing all items on the spirituality scale, and the overall mean was imputed for these participants. Results did not differ when these participants were removed from analyses.

Transformations. Among study variables, GPA and spirituality were negatively skewed and substance use and community service were positively skewed. Skewness was corrected after conducting square root (spirituality; community service) and log transformations (GPA; substance use). However, the substance use scale was still skewed after transformations but was treated as a continuous variable in regression analyses.

Correlations. Bivariate correlations were run between all predictors and outcome variables. Both religious behavior and spirituality were positively correlated with GPA and volunteering and negatively correlated with substance use (see Table 1).

\section{Primary analyses}

Three hierarchical linear regression analyses were run to examine if religious behavior, spirituality, and geographic location were predictive of adolescent GPA, substance use, and community service. First, continuous predictors including age, religious behavior, and spirituality were centered and interaction terms were created from centered variables. Demographic variables (gender, SES, and age) were included in step one of each regression, religious behavior, spirituality, and location were added to the model at step two, and two-way 
interaction terms including religious behavior $\mathrm{X}$ spirituality, religious behavior $\mathrm{X}$ location, and spirituality X location were included in step three. Finally, a three-way religious behavior X spirituality X location interaction term was entered into the final step of each model (see Table 2).

Religious behavior and spirituality each were positively associated with GPA, but these unique effects were qualified by a religious behavior X spirituality interaction. Religiously involved adolescents who were high in spirituality had higher GPAs than religious youth low in spirituality (see Figure 1). School was also positively related to GPA such that city youth had higher GPAs than rural youth. Finally, GPA was negatively related to age. Religious behavior was also associated with increased community service while spirituality was not significantly associated with community service.

Substance use was positively associated with age such that older youth were more likely to engage in substance use. Religious behavior was associated with lower levels of substance use while spirituality was not significantly associated with substance use for any youth. However, for city youth, the association between religious behavior and illicit substance use was qualified by a religious behavior x spirituality x location three-way interaction. Specifically, religious behavior was associated with increased substance use for city youth who were low in spirituality (see Table 3 and Figure 2). For rural youth, religious behavior was negatively associated with substance use and the spirituality $\mathrm{X}$ religious behavior interaction was not significant.

\section{Discussion}

The current study examined religious behavior, spirituality, and adolescent outcomes including grade point average (GPA), illicit substance use, and community service, and tested whether these associations varied as a function of geographic location (city vs. rural). Results 
indicated that net of spirituality, adolescent religious behavior was associated with higher grade point averages, greater levels of community service, and lower levels of substance use. Over and above religious behavior, spirituality also predicted higher GPA and lower substance use among all youth. However, this association was qualified such that religious behavior actually predicted higher substance use in city youth who were not also spiritual.

Overall, findings support previous research which has found that religious behavior and spirituality are beneficial for youth (e.g. Milot \& Ludden, 2009), though the current study adds to the existing literature on youth religious development in a number of ways. Much of the previous research has combined several components of religiosity including both behavioral and psychological dimensions into a single variable (McNamara \& Nelson, 2008). Findings illustrate the importance of distinguishing religious behavior from spirituality, as these two facets of youth religiosity appear to operate differentially in predicting a diverse range of youth outcomes. The current study demonstrates that religious behavior and spirituality synergistically predict youth outcomes such as academic performance and substance use. Specifically, the protective effects of religious behavior manifest differently for youth high versus low in spirituality. This suggests that while certain aspects of simply attending church, such as social capital (King \& Furrow, 2004) may be beneficial for youth, feeling a connectedness to a higher power is also important for certain outcomes. Potentially, youth who feel a connectedness to a higher power may feel intrinsically motivated to attend religious services and this motivation may translate to other areas of their lives, such as completing school work and avoiding delinquent behavior.

Finally, the current study shows different patterns in these associations for city vs. rural youth. This finding suggests that religious behavior may look differently for youth living in varying contexts. Participation in church activities may give rural youth a unique environment to 
meet and interact with youth who have similar prosocial values, such as academic performance (Ferris et al., 2013).

Religious behavior may be particularly important for positive youth outcomes because of the support and resources the social environment of church provides. Specifically, religious organizations typically provide a social framework in which adolescents find support, trust, and guidance (Bartkowski \& Xu, 2007; Glanville et al., 2008; Hodge et al., 2001; King \& Furrow, 2004). The protective effects of this level of social support may be especially important for influencing youth's performance in school, as church involvement may give adolescents the opportunity to engage with youth who value academic achievement (Ferris et al., 2013; Glanville et al., 2008). Further, youth who feel connected to a higher power may value the church environment to a greater degree than youth who attend for more external reasons, such as family obligation. Concordantly, these youth may also more value their church relationships and, therefore, benefit more from the academic resources available through the social network of the church. Finally, spirituality may be important for adolescent GPA as it may lead adolescents to value discipline, which translates to higher academic achievement (Ferris et al., 2013).

The current study also found that religious behavior is predictive of community service, while spirituality was not. Research has consistently found that church attendance is predictive of community service during adolescence (Ferris et al., 2013; Gibson, 2008; Lam, 2002; Monsma, 2007; Paxton et al., 2014). One possible explanation for this could be that the social ties youth form in church may promote a need to care for others (Lewis, MacGregor, \& Putnam, 2013). The supportive social networks and promotion of values embedded within religious organizations may also provide increased opportunities for adolescents to participate in pro-social civic activities, such as community service. Specifically, religious organizations often offer 
community outreach programs which provide opportunities for religious adolescents to participate in community service behaviors, as well as promote values consistent with participating in community service (Paxton et al., 2014). Youth who attend religious services have equal access to participate in these community service activities regardless of their connectedness to a higher power, which may explain why spirituality was not associated with adolescent community service nor did religious behavior's relationship to community service vary based on level of religious spirituality.

In contrast to GPA and volunteering, however, both religious behavior and spirituality were associated with lower substance use. Religious organizations often offer youth programs which may be directly aimed at teaching youth about the importance of avoiding problematic behaviors, such as substance use (Kutter, 1993). The positive supportive structure of the religious environment has also been found to be associated with increased trust in parents, friends, and other adults (King \& Furrow, 2004) which may motivate youth to avoid engaging in problematic behaviors. Specifically, religious institutions provide rural youth with a unique social environment which allows them to interact with members of the community with whom they may not interact with elsewhere in a minimally populated area (Ferris et al., 2013). This may aid in explaining why religious behavior was associated with lower substance use for rural youth in the current study. Further, social relationships in a religious setting may be differentially important in preventing these behaviors in highly populated areas, such as cities, as youth in these areas may have greater access to and be exposed to these illicit substances at a young age (Mennis \& Mason, 2012). Additionally, adolescents who participate in church-related activities have decreased exposure to problematic peers (Schreck et al., 2007; Smith, 2003), further decreasing opportunities to engage in illicit substance use. It has been theorized that 
connectedness to a higher power may also intrinsically motivate individuals to more closely live in accordance with the religion's teaching concerning problematic health behaviors (Hodge et al., 2001; McNamara \& Nelson, 2008). Spirituality also fosters feelings of positive self-image and self-esteem (Ellison, 1993), which may lead to an increased ability to avoid self-harming behaviors, such as substance use (Hodge et al., 2001). This may help to explain why city youth high in spirituality participated in less substance use than youth low in spirituality.

\section{Limitations and Future Directions}

The current study has several limitations which are important to consider. First, selfreport measures are susceptible to social desirability biases, which could be of particular concern as adolescents typically over report GPA (Schwartz \& Beaver, 2015) and under report substance use (Thayer \& Hutchinson, 2012). Further, despite transformations, substance use remained notably skewed, which may limit interpretation of findings.

In addition, while religious behavior and spirituality were differentially predictive of youth outcomes, they were also significantly correlated at .71 which led to slightly higher statistical indications of multicollinearity. Across regressions, VIF ranged from 1.01 - 4.43. While diagnostics indicate slight problems with multicollinearity, these diagnostics were still within acceptable limit (Alin, 2010) and the moderately high correlation between religious behavior and spirituality made conceptual sense and allowed researchers to proceed with interpretation of findings.

In addition, the measures used to explore religious behavior and spirituality only capture certain components of religiosity. As noted above, there are several ways to operationalize these constructs, such as participation in spiritual practices like prayer (Good et al., 2011). Finally, the cross-sectional nature of the study does not allow for causal associations to be inferred. 
Research is needed to consider the influence of other components of religious behavior and spirituality on positive youth outcomes. Specifically, future investigations could include other measures of spirituality that may not be as highly correlated with the current measure of religious spirituality to help alleviate problems with multicollinearity such as non-religious spirituality (Hyland et al, 2010). Future research could also consider a wider array of adolescent outcomes, such as risky sexual behavior. In addition, future research should incorporate longitudinal designs to explore causal associations between these variables as well as to explore potential mediators between religious behavior, spirituality, and adolescent outcomes, such as social support within a religious community. Finally, the current findings should be replicated in more diverse samples including a wider array of race/ethnicities as well as religious backgrounds to allow for increased generalizability across youth.

\section{Conclusion}

The current study supported the idea that behavioral and psychological aspects of religiosity and spirituality manifest differently in positive youth outcomes. Specifically, religious behavior and spirituality operated differentially and interactively in their relationship to adolescent academic performance, community service, and illicit substance use. These associations also vary by geographic location, such as living in a rural or city environment, which illustrates the importance of examining and comparing these associations across a variety of youth contexts. Overall, findings showcase the importance of disaggregating religious behavior from spirituality and examining the unique and interactive influence of these constructs in positive youth outcomes. 
References

Alin, A. (2010). Multicollinearity. Wiley Interdisciplinary Reviews: Computational Statistics, 2(3), 370-374. doi: 10.1002/wics.84

Bartkowski, J. P. \& Xu, X. (2007). Religiosity and teen drug use reconsidered: A social capital perspective. American Journal of Preventive Medicine, 32(6), 182-194.

doi:10.1016/j.amepre.2007.03.001

Benson, P., Roehlkepartain, E., \& Rude, S. (2003). Spiritual development in childhood and adolescence: Toward a field of inquiry. Applied Developmental Science, 7(3), 205-213. doi:10.1207/S1532480XADS0703_12

Benson, P. L, Scales, P. C., Sesma, A., \& Roehlkpartain, E. C. (2005). Adolescent spirituality. In K. A. Moore, \& L. Lippman (Eds.), What do children need to flourish? Conceptualizing and measuring indicators of positive development ( $1^{\text {st }}$ ed., pp. 25-40). New York, NY: Springer.

Eccles, J. S., Barber, B. L., Stone, M. \& Hunt, J. (2003). Extracurricular activities and adolescent development. Journal of Social Issues, 59(4), 865-889. doi:10.1046/j.00224537.2003.00095.x

Ellison, C. (1993). Religious involvement and self-perception among black Americans. Social Forces, 71(4), 1027-1055. doi:10.2307/2580129

Ferris, K. A., Oosterhoff, B., Metzger, A. (2013). Organized activity involvement among rural youth: Gender differences in associations between activity type and developmental outcomes. Journal of Research in Rural Education, 28(15), 1-16. 
Flor, D. \& Knapp, N. (2001). Transmission and transaction: Predicting adolescents’ internalization of parental religious values. Journal of Family Psychology, 15(4), 627645. doi:10.1037/0893-3200.15.4.627

Gibson, T. (2008). Religion and civic engagement among America's youth. Social Science Journal, 45, 504-514. doi:10.1016/j.soscij.2008.07.007

Glanville, J. L., Sikkink, D., \& Hernández, E. I. (2008). Religious involvement and educational outcomes: The role of social capital and extracurricular participation. The Sociological Quarterly, 49(1), 105-137. doi:10.1111/j.1533-8525.2007.00108.x

Good, M., Willoughby, T., \& Busseri, M. (2011). Stability and change in adolescent spirituality/religiosity: A person-centered approach. Developmental Psychology, 47(2), $538-550$.

Hackerman, A. \& King, P. (1998). Adolescent Spirituality. Alcoholism Treatment Quarterly, 16, 89-99. doi:10.1300/J020v16n03_08

Haug, I. (1998) Spirituality as a dimension of family therapists' clinical training. Contemporary Family Therapy, 20(4), 471-483.

Hill, P. C., Pargament, K. I., Hood, R. W., McCullough, M. E., Swyers, J. P., Larson, D. B., \& Zinnbauer, B. J. (2000). Conceptualizing religion and spirituality: Points of commonality, points of departure. Journal for the Theory of Social Behaviour, 30(1), 0021-8308. doi:10.1111/1468-5914.00119

Hodge, D. R., Cardenas P., \& Montoya, H. (2001). Substance use: Spirituality and religious participation as protective factors among rural youths. Social Work Research, 25, 153161. 
Hyland, M. E., Wheeler, P., Kamble, S. \& Masters, K.S. (2010). A sense of' special connection', self-transcendent values and a common factor for religious and non-religious spirituality. Archive for the Psychology of Religion, 32(3), 293-326. doi:10.1163/157361210x533265

Keretes, M., Youniss, J., \& Metz, E. (2004). Longitudinal patterns of religious perspective and civic integration. Applied Developmental Science, 8, 39-46. doi:10.1207/S1532480XADS0801_5

King, P. E., \& Furrow, J. L. (2004). Religion as a resource for positive youth development: religion, social capital, and moral outcomes. Developmental Psychology, 40(5), 703-713. doi:10.1037/1941-1022.S.1.34

King, P., \& Roeser, R. (2008). Handbook of adolescent psychology: Individual bases of adolescent development (Vol. 1) (3rd ed.). Hoboken, NJ: John Wiley \& Sons, INC.

Kutter, C., \& McDermott, D. (1993). The role of the church in adolescent drug education. Brain Research Reviews, 27(3), 293-305. doi:10.1177/0192513X12437708

Lam, P. (2002). As the flocks gather: How religion affects voluntary association participation. Journal for the Scientific Study of Religion, 41(3), 405-422. doi:10.1111/14685906.00127

Lewis, V. A., MacGregor, C. A., \& Putnam, R. D. (2013). Religion, networks, and neighborliness: The impact of religious social networks on civic engagement. Social Science Research, 42(2), 331-346. doi:10.1016/j.ssresearch.2012.09.011

Mason, M. J., Schmidt, C. \& Mennis, J. (2012). Dimensions of religiosity and access to religious social capital: Correlates with substance use among urban adolescents. Journal of Primary Prevention, 33(5-6), 229-237. doi:10.1007/s10935-012-0283-y 
McNamara, B. C., \& Nelson, L. J. (2008). The role of religious beliefs and practices on emerging adults' perceived competencies, perceived importance ratings, and global self-worth. International Journal of Behavioral Development, 32, 509-521. doi:10.1177/0165025408095555

Mennis, J. \& Mason, M. J. (2012). Social and geographic contexts of adolescent substance use: The moderating effects of age and gender. Social Networks, 34(1), 150-157. doi:10.1016/j.socnet.2010.10.003

Metzger, A., Crean, H. F., \& Forbes-Jones, E. L. (2009). Patterns of organized activity participation in urban, early adolescents: Associations with academic achievement, problem behaviors, and perceived adult support. The Journal of Early Adolescence, 29(3), 426-442. doi:10.1177/0272431608322949

Miller, W. R., \& Thoresen, C. E. (2003). Spirituality, religion, and health: An emerging research field. American Psychologist, 58(1), 24-35. doi:10.1037/0003-066X.58.1.24

Milot, A. S., \& Ludden, A. B. (2009). The effects of religion and gender on well-being, substance use, and academic engagement among rural adolescents. Youth \& Society, 40(3), 403-425. doi:10.1177/0044118X08316668

Monsma, S. (2007). Religion and philanthropic giving and volunteering: Building blocks for civic responsibility. Interdisciplinary Journal of Research on Religion, 3(1), 1-28.

Oosterhoff, B., Ferris, K. A., \& Metzger, A. (2014). Adolescents' sociopolitical values in the context of organized activity involvement. Youth \& Society, 1-21. doi:10.1177/0044118X14560528 
Paxton, P., Reith, N., \& Glanville, J. L. (2014). Volunteering and the dimensions of religiosity: A cross-national analysis. Review of Religious Research, 56, 597-625. doi:10.1007/s13644-014-0169-y

Schreck, C. J., Burek, M. W., \& Clark-Miller, J. (2007). He sends rain upon the wicked: A panel study of the influence of religiosity on violent victimization. Journal of Interpersonal Violence, 22(7), 872-893. doi:10.1177/0886260507301233

Schwartz. J. A., \& Beaver, K. M. (2015). Making (up) the grade? Estimating the genetic and environmental influences of discrepancies between self-reported grades and official GPA scores. Journal of Youth and Adolescence, 44(5), 1125-1138. doi:10.1007/s10964-0140185-9

Shahabi, B. A. et al. (2002). Correlates of self-perceptions of spirituality in American adults. Annals of Behavioral Medicine, 24(3), 59-68. doi:10.1207/S15324796ABM2401_07

Sinha, J. W., Cnaan, R. A., \& Gelles, R. J. (2007). Adolescent risk behaviors and religion: Findings from a national study. Journal of Adolescence, 30, 231-249. doi:10.1016/j.adolescence.2006.02.005

Smetana, J. G., \& Metzger, A. (2005). Family and religious antecedents of civic involvement in middle class African American late adolescents. Journal of Research on Adolescence, 15(3), 325-352. doi:10.1111/j.1532-7795.2005.00099.x

Smith, C. (2003). Religious participation and network closure among American adolescents. Journal for the Scientific Study of Religion, 42(5), 259-267. doi:10.1111/14685906.00177

Smith, C., \& Denton, M. L. (2005). Soul Searching: The Religious and Spiritual Lives of American Teenagers. Cary, NC, USA: Oxford University Press. 
Smith, C., Denton, M. L., Faris, R., \& Regnerus, M. (2002). Mapping American adolescent religious participation. Journal for the Scientific Study of Religion, 41(4), 597-612.

Thayer, R. E. \& Hutchison, K. E. (2012). Improving accuracy of adolescents' substance use reports via text messaging. Addiction, 5, 1015-1016. doi:10.1111/j.1360-

0443.2011.03768.x 


\section{Appendix A \\ Figures and Tables - Primary Analyses}

Table 1

Correlations Among and Descriptive Statistics for Key Study Variables $(\mathrm{N}=743)$

\begin{tabular}{|c|c|c|c|c|c|c|c|c|}
\hline & $M(S D)$ & Age & SES & $\begin{array}{l}\text { Religious } \\
\text { Behavior }\end{array}$ & Spirituality & GPA & $\begin{array}{c}\text { Substance } \\
\text { Use }\end{array}$ & Volunteer \\
\hline Age & $15.87(1.28)$ & & $-.09 *$ & $-.09 *$ & -.07 & $-.19 * *$ & $.20 * *$ & $\begin{array}{l}-.01 \\
\end{array}$ \\
\hline SES & $2.75(0.79)$ & & & $.12 * *$ & .02 & $.25 * *$ & -.05 & .07 \\
\hline $\begin{array}{l}\text { Religious } \\
\text { Behavior }\end{array}$ & $2.64(1.36)$ & & & & $.71 * *$ & $.21 * *$ & $-.17 * *$ & $.33 * *$ \\
\hline Spirituality & $3.98(1.50)$ & & & & & $.08^{*}$ & $-.15^{* *}$ & $.23 * *$ \\
\hline GPA & $5.61(1.31)$ & & & & & & $-.25 * *$ & $.13^{* *}$ \\
\hline Substance Use & $1.28(0.52)$ & & & & & & & $-.14 * *$ \\
\hline Volunteer & $2.50(0.91)$ & & & & & & & \\
\hline
\end{tabular}


Table 2

Summary of Hierarchical Regression Analysis for Religious Behavior and Spirituality Predicting Youth Outcomes $(\mathrm{N}=739)$

GPA Substance Use Community

Service

\begin{tabular}{|c|c|c|c|c|c|c|c|c|c|c|c|c|}
\hline & $\mathrm{F}$ & $\mathrm{R}^{2}$ & $\mathrm{~B}$ & $\beta$ & $\mathrm{F}$ & $\mathrm{R}^{2}$ & $\mathrm{~B}$ & $\beta$ & $\mathrm{F}$ & $\mathrm{R}^{2}$ & B & $\beta$ \\
\hline Step 1 & $25.26 * * *$ & .31 & - & - & $11.30 * * *$ & .04 & - & - & $2.72 *$ & .01 & - & - \\
\hline Gender & - & - & .07 & .03 & - & - & -.00 & -.04 & - & - & .03 & .04 \\
\hline SES & - & - & $.31 * * *$ & .18 & - & - & -.00 & -.03 & - & - & .02 & .05 \\
\hline Age & - & - & $-.14 * * *$ & -.13 & - & - & $.02 * * *$ & .19 & - & - & .01 & .02 \\
\hline Step 2 & $15.81 * * *$ & .39 & - & - & $6.24 * * *$ & .07 & - & - & $28.55 * * *$ & .11 & - & - \\
\hline Rel. B. & - & - & $.24 * *$ & .24 & - & - & $-.03 * * *$ & -.10 & - & - & $.09 * * *$ & .40 \\
\hline Spirit. & - & - & -.35 & -.12 & - & - & .01 & -.07 & - & - & -.04 & -.06 \\
\hline Loca. & - & - & $.50 * * *$ & .19 & - & - & .02 & -.07 & - & - & -.05 & -.09 \\
\hline Step 3 & $4.31 * *$ & .41 & - & - & $5.01 * *$ & .09 & - & - & .44 & .12 & - & - \\
\hline $\begin{array}{l}\text { Rel. B. } \\
\text { X } \\
\text { Spirit. }\end{array}$ & - & - & $.39 * *$ & .16 & - & - & .01 & -.09 & - & - & -.02 & -.04 \\
\hline $\begin{array}{l}\text { Rel. B. } \\
\text { X } \\
\text { Loca. }\end{array}$ & - & - & -.11 & -.08 & - & - & $.04 * * *$ & .57 & - & - & -.03 & -.10 \\
\hline $\begin{array}{l}\text { Spirit.x } \\
\text { Loc. }\end{array}$ & - & - & .42 & .10 & - & - & $-.07 *$ & -.31 & - & - & .05 & .05 \\
\hline Step 4 & 2.47 & .41 & - & - & $8.30 * *$ & .10 & - & - & 1.01 & .12 & - & - \\
\hline $\begin{array}{l}\text { Rel. B. } \\
\text { x } \\
\text { Spirit. } \\
\text { x Loc. }\end{array}$ & - & - & -.28 & -.09 & - & - & $-.05 * *$ & -1.62 & - & - & .04 & .06 \\
\hline
\end{tabular}






Figure 1. Religious Behavior X Spirituality Predicting GPA 
Table 3

Hierarchical Regression Analysis for Religious Behavior and Spirituality Predicting Substance Use for City vs. Rural Youth $(\mathrm{N}=739)$

\begin{tabular}{|c|c|c|c|c|c|c|c|c|}
\hline & \multicolumn{4}{|c|}{ City } & \multicolumn{4}{|c|}{ Rural } \\
\hline & $\mathrm{F}$ & $\mathrm{R}^{2}$ & B & $\beta$ & $\mathrm{F}$ & $\mathrm{R}^{2}$ & B & $\beta$ \\
\hline Step 1 & $17.46^{* * *}$ & .13 & - & - & 2.17 & .12 & - & - \\
\hline Gender & - & - & .02 & .02 & - & - & -.01 & -.05 \\
\hline SES & - & - & .00 & .02 & - & - & -.01 & -.05 \\
\hline Age & - & - & $.04 * * *$ & .35 & - & - & .00 & .03 \\
\hline Step 2 & 2.68 & .37 & - & - & $11.06^{* * *}$ & .07 & - & - \\
\hline Rel. B. & - & - & .01 & .13 & - & - & $-.03 * *$ & -.29 \\
\hline Spirit. & - & - & $-.06 * *$ & -.20 & - & - & .01 & .04 \\
\hline Step 3 & $12.90 * * *$ & .41 & - & - & 1.20 & .08 & - & - \\
\hline Rel. B. x Spirit. & - & - & $-.05 * * *$ & -.18 & - & - & .02 & .06 \\
\hline
\end{tabular}




\section{City}

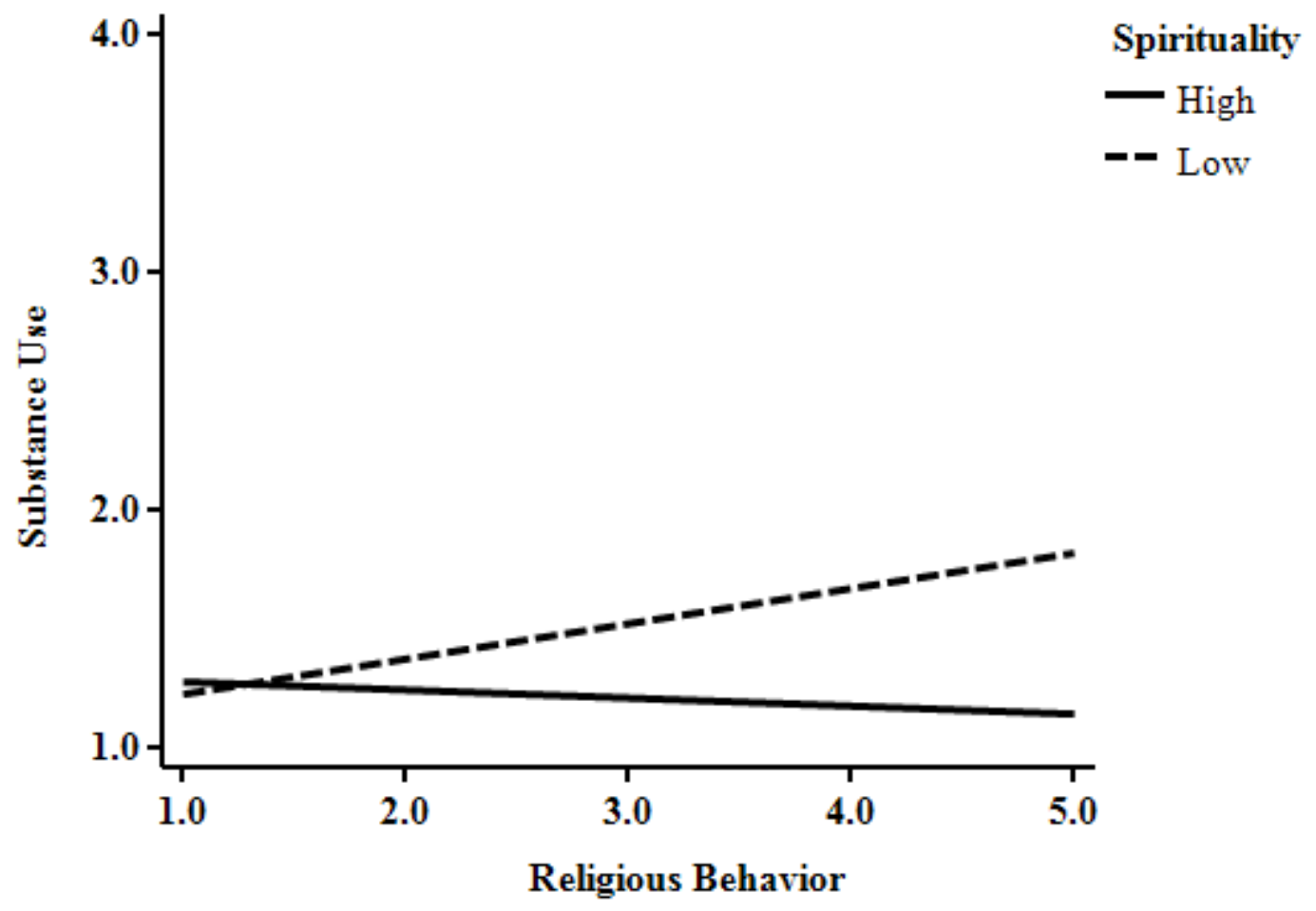

Figure 2. Religious Behavior and Spirituality Predicting Substance Use for City Youth 


\section{Appendix B \\ Additional Manuscript Analyses}

\section{Transformations}

Among study variables, GPA and spirituality were negatively skewed and substance use and community service were positively skewed. A square root transformation was performed on all variables. This corrected the skewness problem for spirituality and community service.

Finally, a logrhythmic transformation was conducted on GPA and substance use. This corrected the skewness problem for GPA, but substance use was still positively skewed.

To investigate limitations with skewness of substance use in interpretation of findings, analyses predicting substance use were reexamined using logistic regressions. For these regressions, a dichotomized substance use variable $(0=$ used no substances, $1=$ used any substances) was used as the outcome variable. Results of the logistic regression did not differ from that of the linear regression. 


\section{Appendix C Extended Literature Review and Methods}

Religiousness and spirituality are multifaceted constructs that play a pivotal role in adolescent development. No fewer than $80 \%$ of teenagers in the United States identify as being part of a particular religion (Smith \& Denton, 2005). Further, religiousness and spirituality have been shown to have important implications across the life-span, but especially for a range of positive youth outcomes including academic performance (Milot \& Ludden, 2009), community service (Ferris et al., 2013), and substance use (Bartkowski \& Xu, 2007). However, previous research has often combined several facets of religiousness into one all-encompassing variable, so the unique and interactive role religious behavior and spirituality play in adolescent development remains unclear (Kub \& Solari-Twadell, 2013). Further, there may be age differences in how these constructs manifest across the course of adolescence or they may operate differently in predicting adolescent outcomes within specific geographic contexts such as city compared to rural contexts. The current study explored associations among religious behavior, spirituality, and three distinct developmental outcomes: academic performance (GPA), and community service, and illicit substance use as well as how these associations vary by adolescent age and geographic location.

Adolescent religiousness and spirituality have been shown to have important implications for a host of positive youth outcomes. A large body of research indicates that religion and spirituality are associated with increased academic performance (Eccles, Barber, Stone, \& Hunt, 2003; Ferris et al. 2013; Glanville et al., 2008; Milot \& Ludden, 2009), greater community service (Ferris et al., 2013; Gibson, 2008; Lam, 2002; Paxton, Reith, \& Glanville, 2014), and reduced levels of problem behaviors such as illicit substance use (Bartkowski \& Xu, 2007; 
Hodge et al., 2001; Metzger et al., 2011; Milot \& Ludden, 2009; Schreck et al., 2007; Sinha et al., 2007). However, religiousness and spirituality have been inconsistently measured throughout the developmental research literature. Previous research has combined the multifaceted construct of religion with components of spirituality, examining them as one variable labeled "religiousness" (Daly, 2005) or "religiosity" (Kub \& Solari-Twadell, 2013) which seem to be used interchangeably throughout the literature. Although more recent investigations have begun to disentangle these constructs and study them separately (e.g. Paxton et al., 2014), the unique role that objective measures of religious behavior and subjective measures of spiritual beliefs (Daly, 2005) contribute to positive youth outcomes remains unclear. Moreover, few studies have examined the ways which religious behavior and spirituality may interact to predict positive youth outcomes. Collectively, the goals of the current study were to examine developmental patterns in adolescents' religious behavior and spirituality as well as the unique and interactive effects of these constructs on positive developmental outcomes in adolescence.

\section{Defining and Measuring Religious Behavior and Spirituality}

Religious Behavior. The relatedness of religion and spirituality makes the differentiation of these constructs a challenging, yet essential task for operationalization and measurement. Across the current body of literature, the definition of religiousness and spirituality has often varied, resulting in inconsistent definitions of these multifaceted variables. One commonly agreed upon component of religiousness, however, is participation in the organized religious practices of an institutionalized faith such as a church, synagogue, or mosque (Haug, 1998; King \& Roesner, 2008; Miller \& Thoresen, 2003). Such practices may include attendance at religious services or participation in religious social or community service activities (Bartkowski \& Xu, 2007; Eccles et al., 2003; Ferris et al., 2013; Gibson, 2008; Glanville et al., 2008; Hodge et al., 
2001; Keretes, Youniss, \& Metz, 2004; King \& Furrow, 2004; Lam, 2002; McNamara \& Nelson, 2008; Metzger et al., 2011; Milot \& Ludden, 2009; Paxton et al., 2014; Schreck et al., 2007; Sinha et al., 2007). However, other components of religiousness have also been examined such as importance of religion (e.g. Sinha et al., 2007). While more current investigations have begun to disaggregated various components of religiousness to isolate these effects, more research is needed to continue to understand how religious behavior differs from other aspects of religiousness in predicting outcomes important to adolescent development.

Spirituality. In addition to religious behavior, psychological components of religion have been examined as predictors of positive outcomes, such as overall well-being across the life span (e.g. Jackson \& Bergeman, 2007), although findings are mixed. For instance, while spirituality has been found to be protective against adolescent substance use as a whole, (Kub \& SolariTwadell, 2013), investigations that have examined various substances separately from each other have found that spiritual trust in God may protect against only some substances, such as alcohol (Barkowski \& Xu, 2007). Moreover, salience of religion has been associated with increased community service overall, yet some research has shown that religious attendance plays a greater role in predicting pro-social behavior than other psychological religious constructs (Monsma, 2007), while others have found evidence supporting the opposite pattern in adults (Paxton et al., 2014). These inconsistencies in the literature call for clearer definition and operationalization of psychological components of religiousness to better understand the nuances of these constructs. One dimension of youth religiousness which may provide clarity to this area of research, as well as encompass multiple psychological facets of religiousness, is spirituality.

While it is perhaps more widely recognized that religious behavior involves attendance and participation in organized religious activities, previous research does not point to a universal 
operationalization of spirituality. However, spirituality is commonly distinguished from religious behavior in that it focuses on what is psychological and personal rather than behavioral and institutional (Haug, 1998; McNamara \& Nelson, 2008). In other words, an individual's spirituality is based on their beliefs and values rather than their participation in certain activities. More specifically, spirituality often refers to a personal belief in a god or other divine being (Benson et al., 2005; Good et al., 2011; Hill et al., 2000), which may or may not be consistent with an institutionalized faith. Spirituality may also refer to a deep connection one has to a sacred being outside of oneself (Benson et al., 2003) or the influence which a higher power has on one's life (Keretes et al., 2004). Still, other definitions of spirituality include the degree of meaning one's spiritual beliefs has to them (Holland et al., 2016), moral standards of living which are put forth by the divine (Haug, 1998), or the frequency one participates in spiritual practices such as prayer and meditation (Good et al., 2011). These definitions share in a common theme which emphasizes a connection to or the importance of a sacred being which transcends the self.

\section{Developmental Trends in Religious Behavior and Spirituality}

Although religious behavior and spirituality are influential experiences in the lives of a substantial portion of youth, participation in religious activities decreases as adolescents become older (Hackerman \& King, 1998; Keretes et al., 2004; Smith et al., 2002). Surveys of youth religious involvement indicate that while $70 \%$ of sixth graders report participating in religious activities at least one hour per week, only $54 \%$ of twelfth graders report this level of religious activity (Benson et al., 2005). It has been theorized that this decline in religious participation may be due, in part, to increased autonomy during adolescence (Smith et al., 2002), as increased choice in their own activities may lead some youth to decide against attending religious 
activities. Thus, older adolescents who continue to participate in religious activities may do so out of personal choice rather than family obligation.

Contrary to this decline in religious involvement, adolescence may be a particularly salient time for spiritual development (Good \& Willoughby, 2008; King, 2003). As youth become older, they develop an increased capability for the levels of abstract thought necessary for in-depth contemplation of their own spiritual beliefs and attitudes (Good \& Willoughby, 2008; Markstrom, 1999). Such questions include those related to the importance of one's existence and the existence of God (Markstrom, 1999). Additionally, shifts in identity development during adolescence often include changes in youth spirituality (Good \& Willoughby, 2008; King, 2003). The formation and development of spiritual beliefs and values are meaningful to adolescent identity formation, as spirituality involves personal commitments to religious beliefs (Markstrom, 1999). Given that identity development and increased cognitive capacities are integral to spiritual development, it might be expected that spirituality would demonstrate normative developmental increases across adolescence. However, due to inconsistencies in definitions of spirituality in previous research, coherent information on the developmental trajectory of spirituality has not yet emerged.

Lack of a consistent operationalization of spirituality has also made it difficult to isolate and distinguish developmental changes in spirituality from change in other facets of religiousness such as religious behavior. The extant research indicates that adolescence may be a time of dramatic shifts in adolescent religiousness which may paradoxically include both decreases in religious behavior but increases in spirituality. Religious behavior has been found to decrease across adolescence, but previous research has not explored the role of spirituality in explicating these developmental patterns. Further, developmental trends in religious behavior 
may manifest differently for adolescents who intrinsically value the spiritual beliefs set forth by their religious organization than those who for more extrinsically motivated related reasons such as family tradition. Specifically, highly spiritual adolescents may continue to stay involved in organized religious activities as they get older.

\section{Religion as a Predictor of Positive Youth Outcomes}

Religious Behavior and Positive Youth Outcomes. Participation in religious activities has been theorized to be uniquely influential in adolescents' lives because religious organizations typically provide a social framework in which adolescents find support, trust, and guidance (Bartkowski \& Xu, 2007; Glanville et al., 2008; Hodge et al., 2001; King \& Furrow, 2004). Unlike the social support youth receive from membership in other types of organizations, religious organizations are often intergenerational and comprised of people who share similar values (Glanville et al., 2008; King \& Furrow, 2004). These connections may aid youth in identity formation and help them "make sense of the world" (King, 2003, p. 198).

Participation in religious activities has also been associated with a host of positive youth outcomes and indicators of youth thriving. Specifically, religious behavior has been linked with greater academic performance (Eccles et al., 2003; Ferris et al., 2013; Glanville et al., 2008; Milot \& Ludden, 2009; Mooney, 2010). Religiously involved adolescents may be motivated to perform well in school because they attend religiously organized youth groups with peers who value academic success and avoid delinquent behavior (Glanville et al., 2008). Religious involvement also leads to greater participation in extracurricular activities which promotes a sense of trust and integrates youth within the school community, leading to academic success (Glanville et al., 2008). 
The supportive social networks and promotion of values embedded within religious organizations may also provide opportunities for adolescents to participate in pro-social civic activities, such as community service. Research has consistently found that church attendance is predictive of community service during adolescence (Ferris et al., 2013; Gibson, 2008; Lam, 2002; Monsma, 2007; Paxton et al., 2014). Religious organizations also offer community outreach programs which provide opportunities for religious adolescents to participate in community service behaviors, as well as promote values consistent with participating in community service (Paxton et al., 2014).

In addition to increasing positive youth outcomes, participation in religious activities has also been shown to be negatively associated with adolescent substance use including decreased smoking (Metzger et al., 2011; Milot \& Ludden, 2009; Sinha et al., 2007), alcohol consumption (Bartkowski \& Xu, 2007; Hodge et al., 2001; Milot \& Ludden, 2009; Schreck et al., 2007, Sinha et al., 2007), and marijuana use (Bartkowski \& Xu, 2007; Milot \& Ludden, 2009; Sinha et al., 2007). Religious organizations often offer youth programs which may be directly aimed at teaching youth about the importance of avoiding problematic behaviors, such as substance use (Kutter, 1993). The consistency of these findings seem to support the theory that qualities of religious organizations, such as a supportive social network, contribute to positive youth outcomes. The positive supportive structure of the religious environment has also been found to be associated with increased trust in parents, friends, and other adults (King \& Furrow, 2004) which may motivate youth to avoid engaging in problematic behaviors and more frequently participate in pro-social activities. Additionally, adolescents who participate in church-related activities have decreased exposure to problematic peers (Schreck et al., 2007; Smith, 2003), further decreasing opportunities to engage in illicit substance use. By promoting positive 
behaviors such as academic success and community service and preventing harmful behaviors such as substance use, participation in religious activities appears to be a strong catalyst for positive youth outcomes.

Spirituality and Positive Youth Outcomes. Relative to studies of religious behavior, fewer studies have explored the protective effects of spirituality, and inconsistencies in measurement of the construct make spirituality's relationship to positive youth outcomes unclear. Despite these issues, youth who reported a strong belief in a personal god volunteered more (Gibson, 2008) and had greater intentions of doing community service in the future than those without these beliefs (Keretes et al., 2004; Smetana \& Metzger, 2005). Further, spirituality, as measured using questions exclusively about connectedness to a higher power has been found to be uniquely associated to reduced substance use including alcohol and marijuana (Hodge et al., 2001; Keretes et al., 2004). It has been theorized that connectedness to a higher power may intrinsically motivate individuals to more closely live in accordance with how they feel the divine being would want them to live (Hodge et al., 2001; McNamara \& Nelson, 2008). Spirituality also fosters feelings of positive self-image and self-esteem (Ellison, 1993), which may lead to an increased ability to avoid self-harming behaviors, such as substance use (Hodge et al., 2001). However, previous research has not fully examined the degree to which spirituality is uniquely associated with positive youth outcomes over and above youths' engagement in religious activities.

\section{The Unique and Interactive effects of Spirituality and Religious Behavior}

Religion and spirituality are often correlated (Shahabi et al., 2002), but the behavioral nature of participation in religious activities and the psychological nature of spirituality may operate differently in predicting youth outcomes. Although there have been multiple calls for 
research to distinguish religious behavior from the beliefs and values associated with spirituality (Benson et al., 2003; Shahabi et al., 2002), few studies have explicitly investigated these potential unique links. Additionally, attempts to disaggregate the behavioral and psychological components of religion and spirituality have been inconsistent, which makes it difficult to articulate a clear message on the relative importance of religious behavior and spirituality for positive youth outcomes. As detailed above, different associations have been found depending on what components of religion and spirituality were examined, and if those components were examined as one variable or separately. To understand how adolescents benefit from their religious and spiritual experiences, it is important that religious behavior be examined independent of spirituality in relation to substance use, academic success, and community service.

Rather than competing, it is equally probable that these two dimensions of religiousness may contribute to positive youth outcomes in a more synergistic fashion. For instance, research indicates that adults who are high in both religious behavior and spirituality engage in greater levels of community service than those adults who only engage in religious behavior or are spiritual (Paxton et al., 2014). This sort of augmentation effect may be present for other facets of positive youth outcomes, as well. For instance, youth who do not internalize spiritual beliefs and values may not participate in risky behaviors such as substance use for the extrinsically motivated reason of avoiding punishment if caught by their social network. However, youth who do feel a strong belief and connectedness to a higher power may avoid such behaviors to an even greater degree if they strongly identify with and personally adhere to religious teachings which discourage the abuse of illicit substances.

\section{Demographic Characteristics of Adolescent Religious Behavior and Spirituality.}


Research has indicated several demographic predictors of highly religious adolescents. Compared to males, female adolescents report far more participation in religious activities (Flor \& Knapp, 2001; Smith et al., 2002). Religious behavior is also greater among rural than urban or suburban youth (Ferris et al., 2013; Shahabi et al., 2002). Finally, religious youth tend to have less educated parents (Shahabi et al., 2002). Similarly to that of religion, certain demographic predictors have been associated with spirituality. Females also tend to be more spiritual than their male counterparts (Shahabi et al., 2002). Empirical findings also suggest that youth of more highly educated parents tend to be more spiritual (Shahabi et al., 2002). Thus, it is important to account for these demographic characteristics when examining correlates of religious behavior and spirituality during adolescence.

\section{Statement of the Problem}

A vast amount of research has examined the role that participation in religious activities, such as attendance at church services and youth groups has on positive youth outcomes. Psychological components of religion have also been found to uniquely predict adolescent outcomes over and above religious behavior. Spirituality is a psychological aspect of religiousness that has been theorized to contribute to positive adolescent outcomes, yet little empirical work has examined the unique contribution that beliefs and connectedness to a higher power have on positive youth outcomes. Further, research that has examined the relationship between spirituality and these behaviors has often incorporated spiritual components into measures of religiousness, preventing researchers from ascertaining whether spirituality, on its own, uniquely contributes to positive youth outcomes over and above youth religious behaviors.

Moreover, although religious behavior been found to decrease from childhood to late adolescence, less research has considered individual differences and heterogeneity in this 
developmental trend. Not all adolescents dramatically reduce their religious attendance as they age and given that religious behavior is consistently linked with positive outcomes, it is important for developmental research to identify the individual characteristics of adolescents who stay religiously involved across adolescence. As adolescents age, they become more autonomous, which may explain why church attendance has been shown to decrease for adolescents over time. However, because adolescents have an increased capability for abstract thought, as well as a need for identity formation, belief and connectedness to a higher power may become increasingly central to their overall development. It is therefore expected that youth who internalize such beliefs, manifested in high degrees of spirituality, will be intrinsically motivated to attend religious services into late adolescence. The first goal of the current study will be to examine age differences in adolescent religious behavior and spirituality and explore how youth spirituality potentially affects age differences in religious behavior.

Research is also needed to examine the unique influences of religious behavior and spirituality on positive youth outcomes. As reviewed above, some theorists posit that the supportive social atmosphere that religious attendance provides is the primary contributor to high academic achievement (e.g. Glanville et al., 2008), increased community service (e.g. Paxton et al., 2014), and lower substance use (e.g. Milot \& Ludden, 2009). Conversely, others argue that internalization of the values commonly promoted by religious institutions is more effective at predicting these positive youth outcomes (e.g. Monsma, 2007; Paxton et al., 2014). Still others attribute these outcomes to the belief and relationship youth may have with a higher power which motivate youth to prioritize positive and avoid negative behaviors (e.g. Hodge et al., 2001; McNamara \& Nelson, 2008). Disaggregating spirituality (personal connection and beliefs) from religious behavior (attendance of religious services and social activities) will aid in determining 
what facets of religiousness are most effective in supporting different aspects of positive youth outcomes.

Even less research has considered potential moderating and mediating associations between religious behavior and spirituality in predicting adolescent outcomes. Outcomes may manifest differently for adolescents who attend religious activities for extrinsic reasons (family obligation) compared to youth who internalize their church's teachings and have a relationship with a higher power. Thus, it is possible that benefits gained from religious behavior and spirituality will interact, resulting in even stronger positive outcomes. Moreover, participation in religious activities may lead to increased community service, which may benefit youth. The second goal of the current study will be to disentangling the unique effects of church attendance and spirituality on adolescent substance use, academic performance, and community service behavior. This study will examine the interactive effects of religious behavior and spirituality on these outcomes. Finally, the current study will investigate the mediating role of community service in the relationship between religious behavior and academic performance and substance use.

\section{Method}

\section{Participants}

Participants consisted of 743 ninth- through twelfth grade students from in a mid-sized University city $(n=367)$ and a rural community $(n=376)$ located in a mid-Atlantic state, between, on average, six and 15 miles from the center of town. Participants were $44 \%$ male and ranged in age from $13-20(M=15.86, S D=1.28)$. In terms of race/ethnicity, $90 \%$ of adolescents reported being Caucasian, 4\% African American, 2\% Asian, 1\% Hispanic, and $<1 \%$ Native American. Approximately $90 \%$ of participants had their mother and $67 \%$ had their father living 
with them in the household and $86 \%$ of moms and $78 \%$ of dads had a high school education or above.

\section{Procedure}

High school students were recruited through their schools. Ninth- through twelfth-grade students were recruited in their social studies classrooms and questionnaires were administered in these classrooms to students who obtained parental consent and assented to participate in the study. Members of the research team were present to explain assent forms and answer participants' questions about the surveys as they were being administered in both schools. Students who participated in the survey were entered into a random drawing to receive cash prizes (16 at each school) ranging from $\$ 25$ to $\$ 100$.

\section{Questionnaire measures.}

Demographics. Adolescents reported their age, gender, and parent's education.

Religious behavior and Community Service. Church involvement (3 items; e.g. "How often do you attend religious services") and community service (5 items; e.g. "How often do you volunteer to clean up your neighborhood, school or community") were assessed using subscales of an organized activity involvement measure based on previous research (Metzger, 2009). Each were rated on a 5-point Likert scale ranging from 1 (never) to 5 (very often). The internal reliability of the church involvement scale is $\alpha=.91$. The internal reliability of the community service scale is $\alpha=.78$.

Religious Spirituality. Adolescent spirituality was measured using 7 items from the Spiritual Transcendence Index (e.g. "I maintain an inner awareness of God's presence in my life"; "My spirituality gives me a feeling of fulfillment") (Seidlitz et al., 2002). Responses were 
given on a 6-point Likert scale ranging from 1 (strongly disagree) to 6 (strongly agree). The internal reliability of this scale is $\alpha=.97$.

GPA. Adolescents self-reported their grades in school using a 7 -point Likert scale $(7=$ mostly A's; 6 = some A's, some B's; $5=$ mostly $B$ 's; 4 = some $B$ 's, some $C$ 's; $3=$ mostly $C$ 's; $2=$ some C's, some D's; 1 = mostly D's or lower .

Illicit substance use. Adolescents' illicit substance use was measured using a 5-item subscale (i.e., had at least one drink of alcohol, gotten drunk off alcohol, smoked cigarettes, smoked marijuana, used prescription pills that were not meant for you) based on previous research (Ferris, et al., 2013; Metzger et al., 2009). Adolescents were asked how often they used these substances in the last 30 days on a 4-point Likert scale ranging from 1 (never) to 4 (often). The internal reliability of this scale is $\alpha=.85$.

\section{Planned Analyses}

Three linear regression models investigated unique and interactive associations between religious behavior, spirituality, geographic context, and three dependent variables: adolescent academic performance, community service, and substance use. In the first step of each regression, adolescent reports of each dependent variable, respectively, were regressed on adolescent age, gender, context (city vs. rural), and parents' education. Adolescent religious behavior, spirituality, and location were then entered into the second step. In the third and fourth step, two- and three-way interaction terms were included, respectively. 


\section{Appendix D Developmental Trends}

Research Question: Are there age differences in levels of youth spirituality and religious behavior in adolescence? Does youth spirituality affect age-related differences in adolescent religious behavior?

Hypothesis: Based on previous research, it is hypothesized that there will be significant age differences in adolescent religious behavior and spirituality, controlling for gender, context, and parent education. More specifically,

a. Younger youth will participate in religious activities more often than older youth.

b. Older youth will be report higher levels of spirituality compared to younger youth.

c. Spirituality will moderate the relationship between religious behavior and age, resulting in consistent religious behavior for highly spiritual adolescents, regardless of age.

Analyses: A linear regression will be conducted to examine age differences in adolescent religious behavior and spirituality. In the first step, religious behavior will be regressed on adolescent gender, context (city vs. rural), and parents' education. Adolescent age and spirituality will be in included in the second step. Finally, an adolescent age X spirituality interaction term will be included in the third step.

Results: To examine adolescent age differences in religious behavior and spirituality, two linear regressions were run. For the first regression predicting religious behavior, demographic variables (gender and SES) were included in step one, age, spirituality, and location were included in the model at step two, and two-way interaction terms including age $\mathrm{X}$ spirituality and location X spirituality were included in step three. Finally, a three-way age X spirituality X 
location interaction term was entered into the final step of the model. For the second regression predicting spirituality, the same demographic variables were included in step one. Next, age, religious behavior, and location were added in the model at step two and two-way interaction terms including age $\mathrm{X}$ religious behavior and location $\mathrm{X}$ religious behavior were included in step three. Last, a three-way age $\mathrm{X}$ religious behavior $\mathrm{X}$ location interaction term was entered into the final step of the model.

Results indicated that religious behavior was predictive of spirituality $\left(\mathrm{R}^{2}=.52, F(3,735)\right.$ $=248.29, p<.001 ; \beta=.68, p<.001)$ and spirituality was predictive of religious behavior $\left(\mathrm{R}^{2}=\right.$ $.51, F(3,735)=249.76, p<.001 ; \beta=.71, p<.001)$. However, age was not predictive of either religious behavior or spirituality. Further, there were no significant interactions predicting religious behavior or spirituality.

Discussion: Findings are inconsistent with previous research which found that younger youth are more likely to attend to religious services that older youth (Keretes et al., 2004). The limited age range of this study may have affected the ability to see age-related differences, as the sample only included ninth- through twelfth-graders. Because adolescent autonomy increases with age, younger adolescents may be more likely to attend church services with their families rather than older youth who make more of their own decisions regarding their behaviors. Further, with age, adolescents' capacity for abstract thought increases which may allow them to more deeply consider complex constructs such as spirituality (Good \& Willoughby, 2008). Therefore, it is likely that had younger participants been included in the sample that age differences between younger and older adolescents in religious behavior and spirituality would have emerged. 


\section{Appendix E Four-way Interaction Terms}

Research Question: How do levels of youth religious behavior and spirituality uniquely contribute to positive youth outcomes? Does adolescent age, location, and spirituality moderate the relationship between religious behavior and positive youth outcomes?

Hypothesis 1: Based on previous research, it is hypothesized that academic performance will be related to religion and spirituality in adolescence. More specifically,

a. Religious behavior and spirituality will be positively associated with adolescent academic performance.

b. Spirituality will amplify the relationship between religious behavior and academic performance, resulting in an even higher academic performance for spiritual adolescents who attend church.

c. Associations between religious behavior, spirituality, and academic performance will be stronger for older youth in a rural geographic context.

Hypothesis 2: Based on previous research, it is expected that religion and spirituality will be associated with community service. More specifically,

a. Religious behavior and spirituality will be positively associated with adolescent community service.

b. Spirituality will amplify the relationship between religious behavior and community service, resulting in even more community service for spiritual adolescents who attend church.

c. Associations between religious behavior, spirituality, and community will be stronger for older youth in a rural geographic context. 
Hypothesis 3: Based on previous research, it is hypothesized that substance use will be related to religion and spirituality in adolescence: More specifically,

a. Religious behavior and spirituality will be negatively associated with adolescent substance use.

b. Spirituality will buffer the relationship between religious behavior and adolescent substance use, resulting in even fewer of these behaviors for spiritual adolescents who attend church.

c. Associations between religious behavior, spirituality, and substance will be stronger for older youth in a rural geographic context.

Analyses: Three linear regression analyses will be used to investigate if religious behavior and spirituality uniquely influence each of three dependent variables: adolescent academic performance, community service, and substance use. In the first step of each regression, adolescent reports of each dependent variable, respectively, will be regressed on adolescent gender and parents' education. Adolescent age, location, religious behavior and spirituality will be entered into the second step. In the third step, two-way interaction terms including age $\mathrm{X}$ location, age $\mathrm{X}$ religious behavior, age $\mathrm{X}$ spirituality, location $\mathrm{X}$ religious behavior, location $\mathrm{X}$ spirituality, and religious behavior X spirituality will be entered into the model. In the fourth step, three-way interaction terms including age $\mathrm{X}$ location $\mathrm{X}$ religious behavior, age $\mathrm{X}$ location $\mathrm{X}$ spirituality, age $\mathrm{X}$ religious behavior $\mathrm{X}$ spirituality, and location $\mathrm{X}$ religious behavior $\mathrm{X}$ spirituality will be included. In the fourth and final step, a four-way age X location X religious behavior X spirituality interaction term will be entered into the model.

Results: Three linear regressions were run to examine the relationship between three youth outcomes: GPA, community service, and substance use, and the unique and interactive 
relationship between adolescent age, location, religious behavior, and spirituality. For GPA, results indicated that the five predictors and two-way interaction terms accounted for approximately $16 \%$ of the variance $\left(\mathrm{R}^{2}=.16, F(6,728)=2.83, p<.05\right)$. Specifically, a significant religious behavior $\mathrm{X}$ spirituality interaction emerged such that religious behavior was positively associated with GPA for youth high in spirituality $(\beta=.10, p<.01$; refer to Figure 1$)$. No three-way or four-way interaction terms were significantly associated with adolescent GPA.

For community service, the five included predictors accounted for approximately $11 \%$ of the variance $\left(\mathrm{R}^{2}=.11, F(4,734)=21.42, p<.001\right)$. Specifically, religious behavior was positively associated with community service $(\beta=.33, p<.001)$. Gender was also associated with community service such that females did significantly more community service than males $(\beta=.08, p<.05)$. No interaction terms were associated with community service.

Finally, results indicated that the five predictor variables accounted for approximately $13 \%$ of the variance $\left(\mathrm{R}^{2}=.13, F(4,724)=3.02, p<.05\right)$. Specifically, a significant location $\mathrm{X}$ religious behavior $\mathrm{X}$ spirituality three-way interaction such that religious behavior was positively associated with substance use for city youth low in spirituality $(\beta=-.20, p<.01$; refer to Figure 2). Results also indicated a significant age $\mathrm{X}$ location interaction such that substance use was positively associated with age for city youth $(\beta=-.22, p<.001$; see Figure 4$)$. No significant four-way interactions for any of the three outcome variables emerged.

Discussion: Overall, findings support the importance of examining religious behavior and spirituality separately as they were differentially associated with each of the three outcome variables. In addition, the association between religious behavior, spirituality, and substance use was found to vary by geographic location which supports the idea that religion and spirituality are differentially important for youth in different contexts. Finally, despite previous research 
which indicated age differences in religious behavior and spirituality (Keretes et al., 2004), the current study did not find that age moderated any of these associations. Similar to research question one, the limited age variability across the current sample may not have been wide enough to capture age differences in these constructs. Future research is needed to further examine the association between religious behavior, spirituality, and adolescent outcomes for youth of all ages and across a variety of contexts (e.g. location, denomination, etc.)

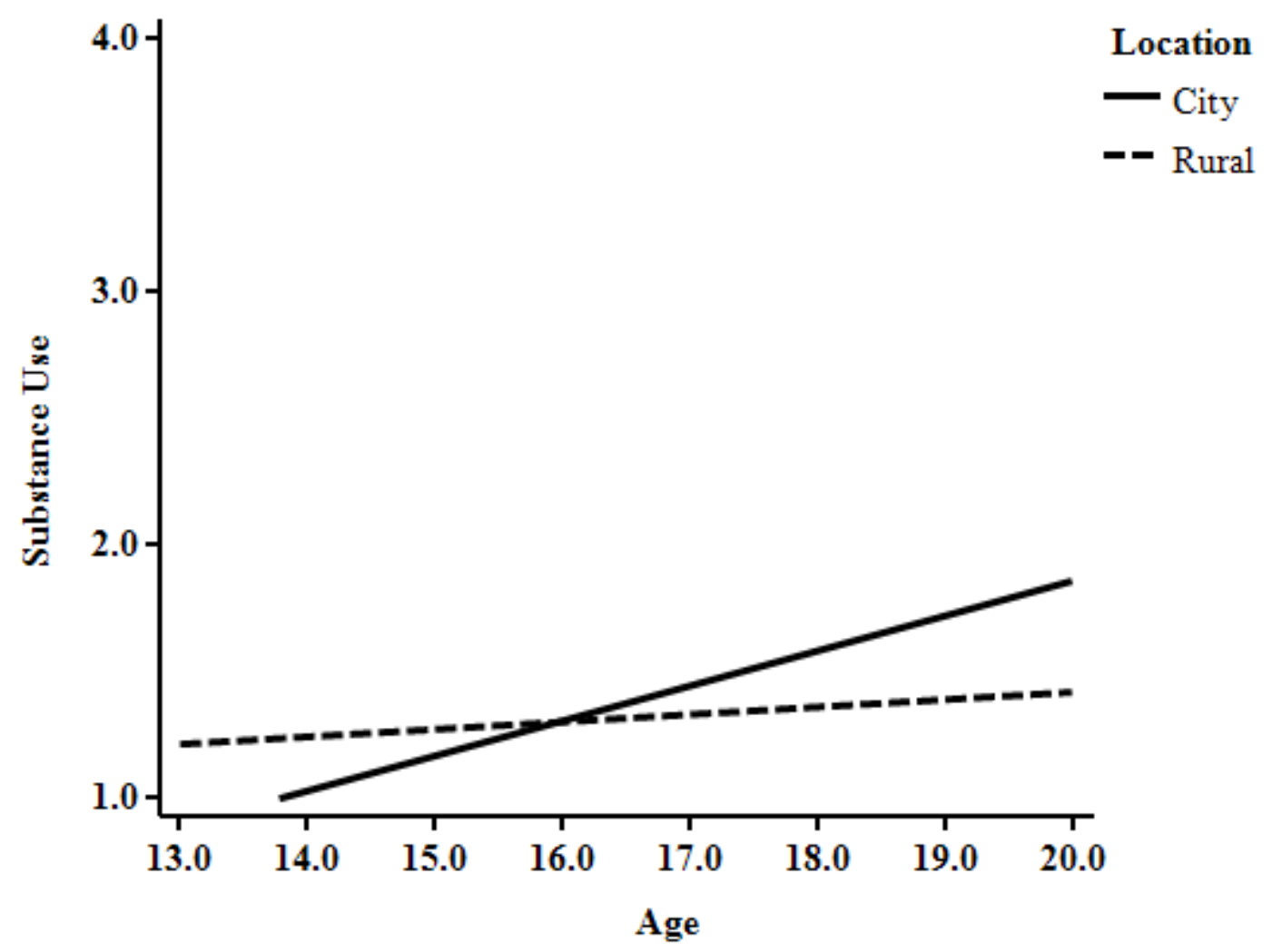

Figure 4. Age X Location Predicting Substance Use 


\section{Appendix F \\ Community Service Mediation}

Research Question: Does community service mediate the relationship between religious behavior and positive youth outcomes?

Hypothesis: Based on previous research, it is expected that religion and spirituality will mediate the relationship between religious behavior and positive youth outcomes. More specifically,

a. Community service will mediate the relationship between religious behavior and academic performance such that religious behavior will be positively associated community service and community service will be positively associated with GPA, thus religious behavior will be positively associated with GPA.

b. Community service will mediate the relationship between religious behavior and substance use such that religious behavior will be positively associated community service and community service will be negatively associated with substance use, thus religious behavior will be negatively associated with substance use.

Analyses: To examine the hypothesis that community service mediated the association between religious behavior and GPA and substance use, two mediation analyses were run using the PROCESS macro by Hayes. For each mediation analysis, religious behavior was entered as the independent variable $(\mathrm{X})$ and community service was entered as the mediator (M). GPA and substance use were then entered into each model as the dependent variable respectively (Y). A conceptual model for the mediation analysis can be found in Figure 5. All analyses were subjected to 1000 follow-up bootstrap analyses and were set at a 95\% confidence interval. Results: First, path $a$ was examined to determine if religious behavior as significantly associated with community service. Next, path $b$ was tested to determine if community service was 
associated with GPA and substance use, respectively. Finally, path c' was tested to examine if community service mediated the association between religious behavior and GPA and substance use.

Results indicated that religious behavior was positively associated with community service $(\beta=.07, p<.001)$, community service was positively associated with GPA $(\beta=.06, p<$ $.05)$, and that community service mediated the association between religious behavior and GPA $(\beta=.03, p<.05)$. Further, results indicated that religious behavior was positively associated with community service $(\beta=.07, p<.001)$, community service was negatively associated with substance use $(\beta=-.05, p<.01)$, and that community service mediated the association between religious behavior and substance use $(\beta=-.01, p<.001)$.

Discussion: Previous research has consistently found a positive association between religious behavior and community service (Ferris, et al., 2013). This could possibly be explained by the opportunities religious institutions often provide for participating in community service. Independent of religious behavior, community service has also been found to be associated with increased GPA and decreased substance use (Eccles \& Barber, 1999). Therefore, it could be that religious behavior serves as a catalyst for positive youth outcomes for providing opportunities to participate in community service. Unfortunately, due to the cross-sectional nature of the current study, true mediation is unable to be determined and future longitudinal research is necessary to determine explanatory links between religious behavior and positive youth outcomes by way of community service. 


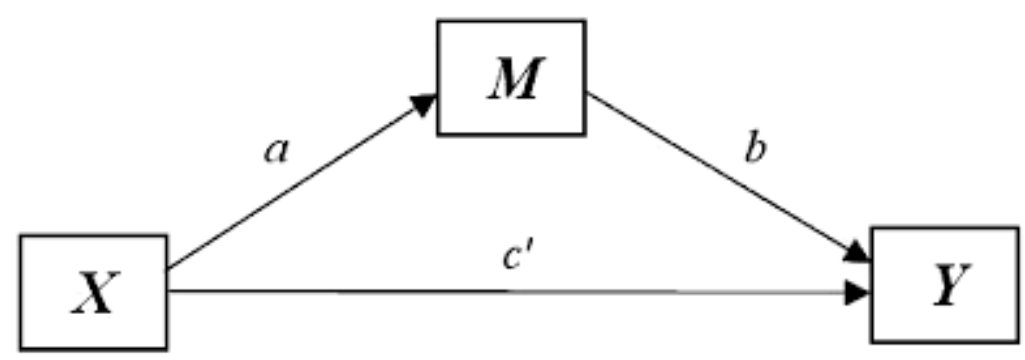

Figure 5. Mediation model by Hayes (2012) 


\section{Appendix G \\ Disaggregated Substance Use}

Exploratory Research Question: Are religious behavior and spirituality uniquely associated with adolescent use of various substances (i.e. alcohol, cigarettes, marijuana, prescription pills)?

Results: Exploratory analyses were conducted to examine the relationship between religious behavior, spirituality, and various illicit substances. Four logistic regression analyses were run to examine each of the following substances including alcohol, cigarettes, marijuana, and prescription medication unintended for participant use using location, religious behavior, and spirituality as predictors (included in the second step), controlling for age and gender (included in the first step). Two-way interaction terms including location $\mathrm{X}$ religious behavior, location $\mathrm{X}$ spirituality, and religious behavior X spirituality, as well as a three-way location $\mathrm{X}$ religious behavior X spirituality interaction term were included in steps three and four of the model, respectively.

Results indicated a significant three-way interaction such that religious behavior was positively associated with substance use for city youth who were low in spirituality for alcohol $(\mathrm{B}=-.75, p<.05)$. Further, the two-way religious behavior $\mathrm{X}$ location interaction term was found to significantly predict cigarette $(\mathrm{B}=.68, p<.01)$ and marijuana use $(\mathrm{B}=.74, p<.01)$. Finally, age was the only predictor of prescription medication use $(\mathrm{B}=.39, p<.01)$.

Discussion: Overall, results were similar across various substance use in adolescence, although the three-way interaction term (location X spirituality X religious behavior) was only significant for alcohol. While previous research has found differences in the association between religious behavior, spirituality, and various substances (Barkowski \& Xu, 2007), substance use as a whole was limited among the current sample. Therefore, it is unclear whether results would have 
differed if more participants had been engaging in substance use. Future research should consider examining these associations in adolescent populations who may be particularly prone to substance use, such as youth living in inner cities (Griffin, Botvin, Scheier, Doyle, \& Williams, 2003). 


\section{Appendix $\mathbf{H}$ \\ Additional References}

Daly, C. (2005). Definition of terms: Spirituality versus religiousness. The Southern Medical Journal, 98(12), 1238-1239. doi:10.1097/01.smj.0000190594.43768.fc

Eccles, J. S. \& Bonnie, B. L. (1999). Student council, volunteering, basketball, or marching band: What kind of extracurricular involvement matters? Journal of Adolescent Research, 14(1), 10-43. doi:10.1177/0743558499141003

Good, M. \& Willoughby, T. (2008). Adolescence as a sensitive period for spiritual development. Child Development Perspectives, 2(1), 32-37. doi:10.1111/j.1750-8606.2008.00038.x

Griffin, K. W., Botvin, G. J. Scheier, L. M., Doyle, M. M. \& Williams, C. (2003). Common predictors of cigarette smoking, alcohol use, aggression, and delinquency among innercity minority youth. Addictive Behaviors, 28(6), 1141-1148. doi:10.1016/S03064603(02)00225-3

Kub, J. \& Solari-Twadell. (2013). Religiosity/spirituality and substance use in adolescence as related to positive development: A literature review. Journal of Addictions Nursing, 24(4), 247-262. doi:10.1097/JAN.0000000000000006

Jackson, B. R. \& Bergeman, C. S. (2011). How does religiosity enhance well-being? The role of perceived control. Psychology of Religion and Spirituality, 3(2), 149-161. doi:10.1037/a0021597

King, P. E. (2003). Religion and identity: The role of ideological, social, and spiritual contexts. Applied Developmental Science, 7(3), 197-204. doi:10.1207/S1532480XADS0703_11

Markstrom, C. A. (1999). Religious involvement and adolescent psychosocial development. Journal of Adolescence, 22(2), 205-221. doi:10.1006/jado.1999.0211 
Metzger, A., Dawes, N., Mermelstein, R., \& Wakschlag, L. (2011). Longitudinal modeling of adolescents' activity involvement, problem peer associations, and youth smoking. Journal of Applied Developmental Psychology, 32(1), 1-9. doi:10.1016/j.appdev.2010.09.005

Mooney, M. (2010). Religion, college grades, and satisfaction among students at elite colleges and universities. Sociology of Religion: A Quarterly Review, 71(2), 197-215. doi:10.1093/socrel/srq035

Seidlitz, L., Abernethy, A., Duberstein, P., Evinger, J., Lewis, B., \& Chang, H. (2002). Development of the spiritual transcendence index. Journal of the Scientific Study of Religion, 41, 439-453. 